\title{
Identification of Rocks and Their Quartz Content in Gua Musang Goldfield Using Advanced Spaceborne Thermal Emission and Reflection Radiometer Imagery
}

\author{
Kouame Yao, Biswajeet Pradhan, and Mohammed Oludare Idrees \\ Department of Civil Engineering, Faculty of Engineering, Universiti Putra Malaysia (UPM), 43400 Serdang, Selangor, Malaysia \\ Correspondence should be addressed to Biswajeet Pradhan; biswajeet24@gmail.com
}

Received 17 January 2017; Accepted 20 February 2017; Published 7 March 2017

Academic Editor: Hyung-Sup Jung

Copyright (C) 2017 Kouame Yao et al. This is an open access article distributed under the Creative Commons Attribution License, which permits unrestricted use, distribution, and reproduction in any medium, provided the original work is properly cited.

\begin{abstract}
Quartz is an important mineral element and the most abundant rock-forming mineral that controls the mineralogy of a reservoir. At the surface, quartz is more stable than most other rock minerals because it is made up of interlocking silica that makes it quite resistant to mechanical weathering. Quartz abundance is an indication of mineralization in many metal deposits; therefore, identification and mapping of quartz in rocks are of great value for exploration and resource potential assessments. In this study, thermal infrared (TIR) bands of the Advanced Spaceborne Thermal Emission and Reflection Radiometer (ASTER) imagery were used to identify quartz contained rocks in Gua Musang. First, the image was corrected for atmospheric effect and the study area subset for further processing. Thereafter, spectral transformation (principal component analysis (PCA)) was implemented on the TIR bands and the resulting principal component (PC) images were analysed. The three optimal PCs were selected using the strength of spectral interaction and the eigenvalues of each band. To discriminate between quartz-rich and quartz-poor rocks, RGB false colour composite and greyscale image of one of the PCs were analysed. The result shows that volcanogenic igneous rock and carbonate sedimentary rocks of Permian formation are quartz-poor while Triassic sedimentary rock made up of organic particles and sandstone is quartz-rich. On the contrary, the quartz content in the metamorphic rock varies across the area but is richer in quartz content than the igneous and carbonate rocks. Classification of the composite image classified using maximum likelihood (ML) supervised classification method produced overall accuracy and Kappa coefficient of $96.53 \%$, and 0.95 , respectively.
\end{abstract}

\section{Introduction}

Malaysia is rich in mineral resources with a long history in gold exploration dated as far back as 1400s. According to the Malaysia 2014 Annual Mining Report released by the Ministry of Energy and Mines, the country is currently ranked as one of the leading producers of gold in Asia, exporting almost $\$ 7$ billion worth of gold in 2009 alone. In an effort to boost the mining industry, the Malaysian government institutionalized mining-friendly policies to attract investors and promote gold mineral exploration. However, geologic mapping and mineral exploration in Malaysia still relies on traditional geological and geophysical site investigations. These methods of mineral prospecting in tropical region like Malaysia are usually faced with several challenges such as limited transportation, harsh climate, and steep terrain with vegetation cover $[1,2]$.

Several studies have been conducted to extract geologic information from satellite remote sensing imagery such as multispectral and hyperspectral data using different processing techniques [3-5]. Advanced Spaceborne Thermal Emission and Reflection Radiometer (ASTER) data have been widely used for geologic mapping due to its sensitivity to rock mineral elements (alunite, kaolinite, calcite, dolomite, chlorite, talc, muscovite, etc.) and low-cost $[6,7]$. The success of spectral transformation from recent investigations [7-10] motivates this research, however, under different topography and vegetation cover.

In this study, ASTER data was used to map quartzrich and quartz-poor rocks zones in Gua Musang goldfield 


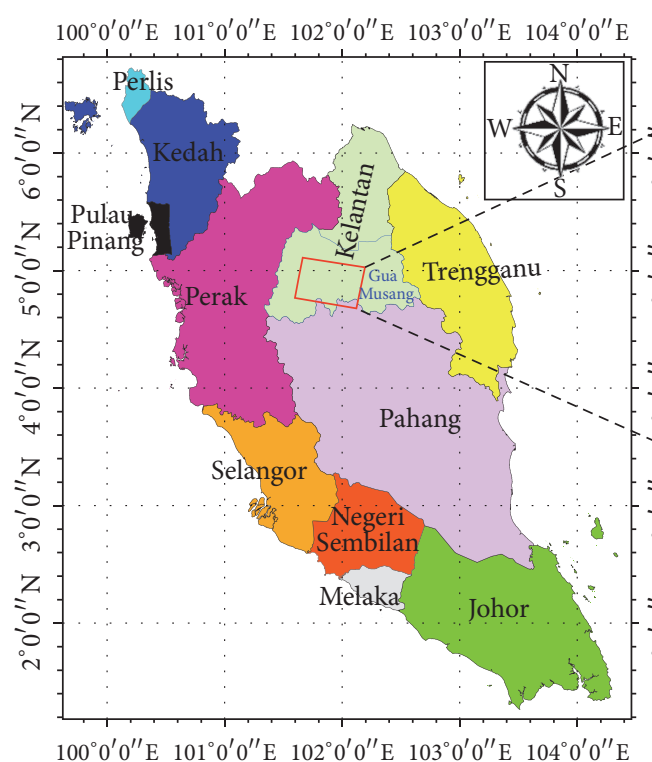

(a)

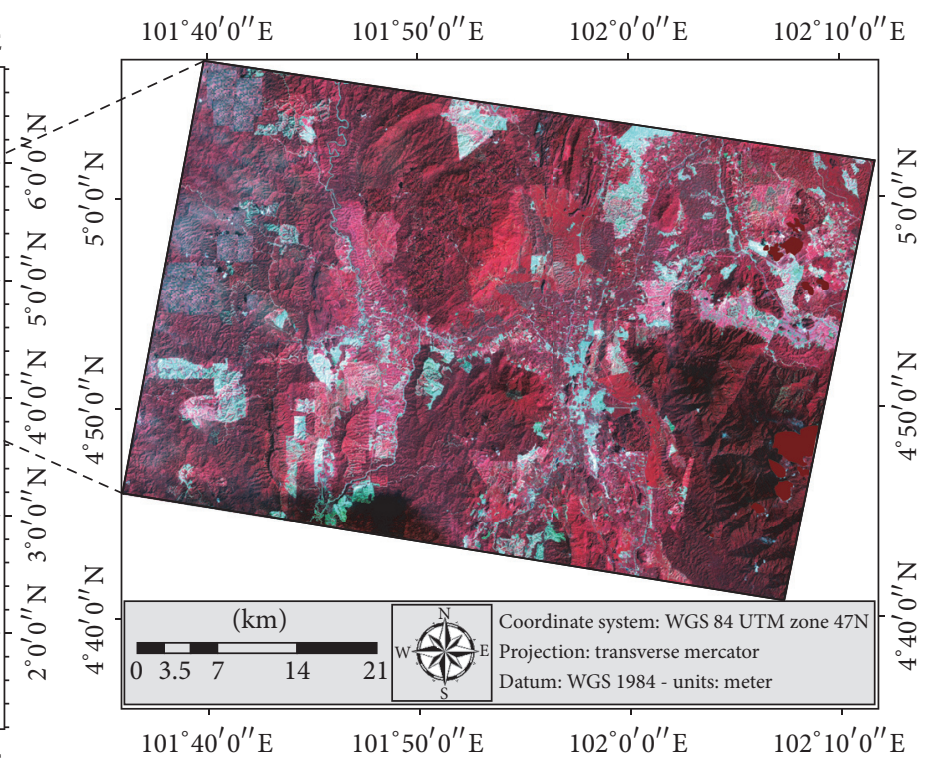

(b)

Figure 1: Location of the study area. Map of Peninsular Malaysia (State of Kelantan in white) and Gua Musang district (a); false colour composite ASTER image of the site (b).

using spectral transformation technique, principal component analysis (PCA). Gua Musang has a long history of gold exploration. This mineralized zone typically consists of goldbearing quartz veins and veinlet. Despite active exploration, prospecting is still based on geochemical and geophysical sampling and analysis [11-14], which is considered time consuming and costly. Again, the tropical nature of the environment and steepness of the terrain limits accessibility.

\section{Geology of the Study Area}

Gua Musang, the largest district in the state of Kelantan, Peninsular Malaysia, is known for its richness in gold mineralization. Geographically, the study area is located between longitudes $101^{\circ} 39^{\prime} 50.86^{\prime \prime} \mathrm{E}$ and $102^{\circ} 7^{\prime} 13.04^{\prime \prime} \mathrm{E}$ and latitudes $4^{\circ} 40^{\prime} 45.65^{\prime \prime} \mathrm{N}$ and $5^{\circ} 6^{\prime} 31.92^{\prime \prime} \mathrm{N}$ (Figure 1). The site is characterized by a mix of forest and sparsely vegetated land cover in predominant agricultural, timber logging and gold mining activities; therefore rock exposure is very minimal. The site is strategically selected to cover the southern gold and silver mercury belts which span the central part of the state in a north-south trending $[13,15]$, measuring about 45124 square kilometres, approximately $0.12 \%$ of Gua Musang territory. The area is characterized with precious minerals and rocks comprising a good spread of hydrothermal quartz veins [13].

The geological evolution of the study area, based on the stratigraphy, geophysical, and volcanic activities, has occasioned different geological pattern in the west, central, and eastern belts $[14,15]$. The surficial lithology of the state of Kelantan comprises igneous, sedimentary, and metamorphic rocks, occurring in a north-south trending that influences the profile of mineralization zones. To the west and eastern border lies igneous rock that forms the main range granite and boundary range granite, respectively [16]. The main range granites belong to the middle Triassic age that comprises intermediate intrusive igneous rock. The central belt of the state is composed of sedimentary and metasedimentary rocks of both Triassic and Permian age. The Triassic sediment is a conglomerate of interbedded sandstone, siltstone, and shale while the Permian counterpart contains phyllite, slate, and shale with subordinate sandstone and schist. Also, the central belt is intersected by intermediate to basic volcano, mainly pyroclastic sediment [12]. Specifically, the study area, Gua Musang, falls south of the state within the central geological formation mostly of the Triassic and Permian sedimentary rocks (Figure 2). Located in the north-central part is an outcrop of igneous rock and also metamorphic rock in the south-western part.

Looking at the mineralization map of Kelantan (Figure 2), it can be observed that the central gold belt extends from the Thai border with Kelantan and almost carpeting the entire subsurface of the state of Pahang. Most of the Malaysian national gold production originates from the Paleo-Arc basin to which the central belt belongs $[14,17]$. Geologically, the belt is composed of fragmented sediments and limestone, as well as igneous rock derived from volcanic and volcanoclastic activities of the Permian to Triassic period [15]. Figure 2(b) is the (digital) geological map of Kelantan.

\section{Materials and Methods}

3.1. Datasets. Advanced Spaceborne Thermal Emission and Reflection Radiometer (ASTER) imagery acquired on the 19th of January, 2011, was used in this study. Detailed description of ASTER sensors and properties of the data can be found in Matar and Bamousa [18] and Pour and Hashim [17]. L1B (level-1B) data of the study area (16\% cloud cover) was made available by NASA Land Processes Distributed 


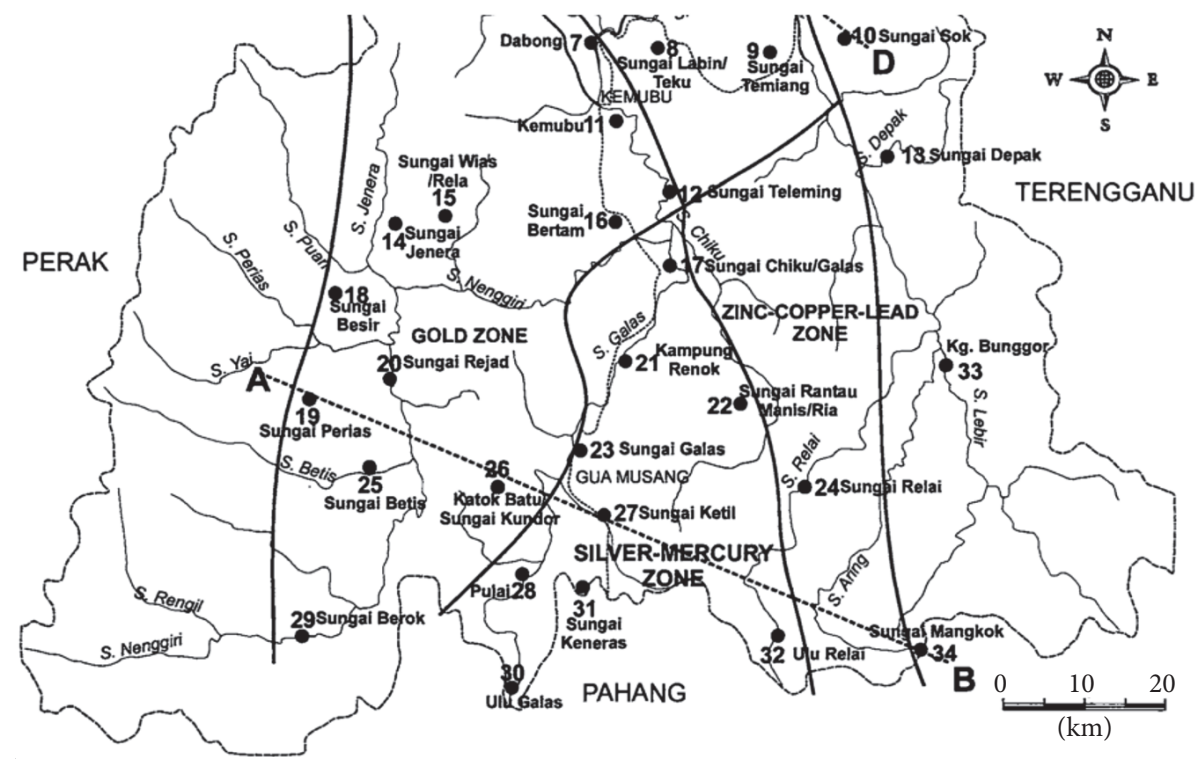

1 Gold prospective area

Zone boundary

Cross section

(a)
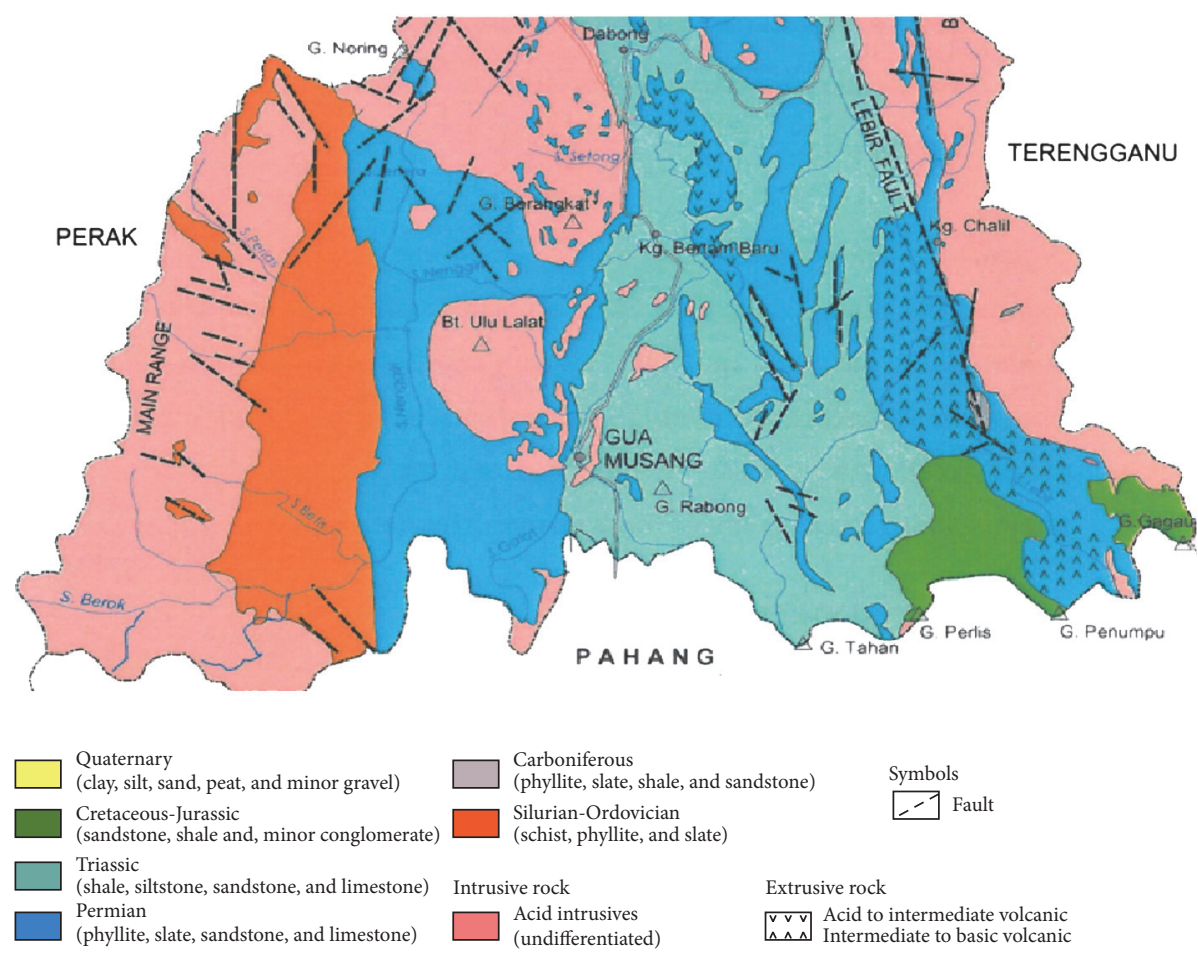

(b)

FIGURE 2: Distribution of mineralization and location of goldfields (modified from [13] p.132) (a). General geology of Kelantan showing the distribution of rocks, source: Nazaruddin (modified from [12]) (b). 
Active Archive Centre (NASA LP DAAC) upon application through the NASA Reverb website (http://reverb.echo.nasa .gov/reverb). The imagery obtained has been corrected for geometric and radiometric effects and projected to universal transverse Mercator (WGS 84). Due to inability of the VNIR and SWIR bands to detect the absorption features of quartz mineral [10], only the TIR bands were used in this study. Within $8-14 \mu \mathrm{m}$, quartz minerals exhibit strong vibrational absorption feature spectrally [5]. The emissivity/absorption features of quartz in the thermal bands are related to structural imbalance in the chemical composition (silica and oxide $-\mathrm{SiO}_{2}$ ) stretching vibration. Natural mineralogy of hydrothermally altered rocks associated with porphyry copper deposits is primarily comprised of quartz veins [19]. In addition to the satellite data, shape file of the digital geological map of the area was obtained from Malaysia's Mineral and Geoscience Department (Figure 2(b)). The digital map was used to visually validate the capability of spectral transform method to accurately identify different rock elements.

3.2. Data Processing. ASTER L-1B data comes preprocessed for radiometric and geometric effect. But like other applications that utilise ASTER/TIR data, this present work depends on the reflectance value of the surface. So, it was necessary to distinguish vegetation area and outcrop areas since ASTER as an optical sensors cannot see through vegetation. This was achieved using NDVI (normalized difference vegetation index). NDVI is a numerical indicator that uses the visible and near-infrared bands of the electromagnetic spectrum to estimate the greenness of vegetation. It has found wide applications in vegetative studies and feature extraction. NDVI values are represented as a ratio -1 to 1 where extreme negative values represent water and values around zero represent bare soil while values over 0.6 represent dense green vegetation. Based on the NDVI values, the result was reclassified into vegetation, cloud, and outcrop using NDVI value of 0.5 and $<0$ to identify vegetation area and cloud.

ASTER L-1B data comes preprocessed for radiometric and geometric effect. Initially, ASTER/TIR was converted to radiance using TIMS radiance tool [20]. Thereafter, the Thermal Atmospheric Correction in ENVI was used to correct the atmospheric effect. The tool employs the In-Scene Atmospheric Compensation algorithm (ISAC) [21] which assumes that the atmosphere is uniform over the scene and that a near-blackbody surface exists within the scene. The first thing the process does is to determine the wavelength that shows the maximum brightness temperature and uses that as the reference wavelength. Only spectra with their brightest temperature at that wavelength are utilised to compute the atmospheric compensation.

Subsequently, the vegetation and cloud affected areas were masked from the calibrated TIR bands to retain only the outcrop area. Further, the effect of the vegetation spectra present in the more exposed area was reduced using forced invariance, a technique that computes images that are invariant relative to the vegetation index [22]. In the resultant images, the vegetation features were considerably suppressed because they contribute insignificant variance.

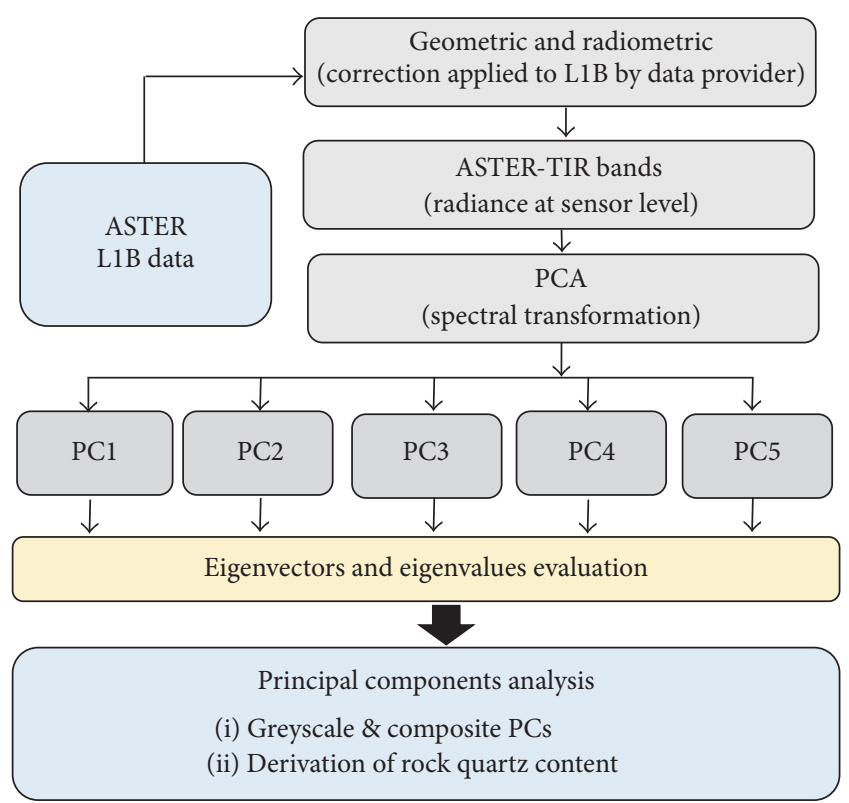

FIGURE 3: Methodological workflow describing the data processing steps.

Finally, TIR image of only the outcrop area was subjected to principal component analysis (PCA). Figure 3 presents the data processing and analysis steps.

\subsection{Method of Analysis}

3.3.1. Spectral Transformation. The occurrence of quartz rock under different forms, colours, and in basically all mineral environments on earth makes distinguishing its richness a difficult task. Particularly, as rock-forming mineral, quartz has no spectral absorption features in the VNIR and SWIR but possesses powerful molecular absorption features in TIR $(8-10 \mu \mathrm{m})$ bands. Away from common lithological mapping using VNIR/SWIR bands $[6,8]$ because of their failure to exhibit absorption features, we used PCA transformation of the ASTER TIR bands to identify quartz richness. Meanwhile, prior to implementing PCA, the vegetation spectra in the image were first suppressed using directed principal component analysis (DPCA). The widespread use of this method for mapping hydrothermal altered rocks, lithology, and other mineralogical applications $[3,4,23-26]$ informed its selection for this study.

PCA is a statistical multivariate method that employs uncorrelated linear combination of variables and transforms them into new dataset containing new correlated variables (eigenvectors loadings) [7, 23, 27]. PCA transform was implemented on the ASTER TIR bands $(10,11,12,13$, and 14) to generate five different principal components ( $\mathrm{PCl}$, PC2, PC3, PC4, and PC5). The strengths and weaknesses, the statistical output, the eigenvectors (Table 1), and their response to quartz content [25] were analysed to select the three PCs components with the highest quality of information to identify quartz richness. For qualitative evaluation of the result obtained from spectral transformation, shapefile of 
TABLE 1: Eigenvectors and eigenvalues for ASTER TIR transformation.

\begin{tabular}{lcccccc}
\hline & Band 10 & Band 11 & Band 12 & Band 13 & Band 14 & \% eigenvalue \\
\hline PCA1 & 0.405888 & 0.449008 & 0.476808 & 0.462932 & 0.438171 & 98.66 \\
PCA2 & -0.504374 & -0.292062 & 0.322006 & -0.265937 & 0.697063 & 0.63 \\
PCA3 & -0.296201 & 0.323920 & 0.686945 & -0.284514 & -0.504480 & 0.36 \\
PCA4 & -0.626402 & 0.615558 & -0.386135 & 0.268850 & 0.055609 & 0.19 \\
PCA5 & 0.317408 & 0.478806 & -0.219028 & -0.749495 & 0.245520 & 0.16 \\
\hline
\end{tabular}

the digital geological map was overlaid on the greyscale image of PC1.

3.3.2. Image Classification. The three selected PCs (PC1, PC3, and PC4) were used to produce RGB false colour composite of the study area which highlights the respective rock elements in different colours. After visual examination of the false colour composite relative to the existing map, the PCs composite image was classified into four different rock types based on quartz richness using supervised classification method and maximum likelihood (ML) classification scheme. ML classifier have been widely used and proven satisfactory to assign pixels in the digital satellite images to particular land cover classes or themes to produce land cover map [28]. Training polygons were digitized on-screen to represent each class based on the spectral representation of the different rocks in the RGB colour composite image and the knowledge from the existing geological map. Some of the training pixels were used for classification and the remaining were used as independent training sets for accuracy assessment to eliminate bias. Once the training sites and classes were assigned, the image was classified into four classes: quartz concentration (quartz-rich and quartz-poor), quartz-rich sedimentary rock, quartz-poor igneous rock, and quartz-poor limestone. Finally, the classification accuracy was evaluated using error matrix.

\section{Results and Discussion}

4.1. PCA Result. The output of a PCA process is the component image accompanied with statistical values of the eigenvector which could carry a positive or negative sign. These signs along with absorption/reflective capacity of specific bands are valuable information required in choosing best components bands for RGB false colour composite. Table 1 presents the eigenvalues of each image band for the respective component analysis.

As mentioned earlier, these TIR bands are useful for identifying silicate and carbonate rocks, while bands 10 and 12 are particularly effective for detecting quartz absorption features and band 14 records high emissivity $[10,29]$. From the eigenvector, positive sign indicates that the band plays a major contribution in the variation of a particular component while negative eigenvalues describe a lesser contribution to the variation of the derived component. The two guiding principles adopted in this study are based on the premise (1) that quartz content can be best determined in bands 10 and 12 where absorption is maximum and band 14 where emissivity is highest and (2) on the condition that the eigenvalues of bands 10 and 12 have positive signs while band 14 is negative [8].

In PC1, for example, the weight matrix is positive and has eigenvalue of $98.66 \%$. When the eigenvalue is positive it indicates high correlation of spectral information among the input image bands, and the nearer the value of the resulting PC component derived is to $100 \%$, the higher the degree of similarity in information contents of images is. According to $[27,30]$, in a situation like this it means that the variance of the variables is at the maximum amount of the variance of the variables which can be accounted for with a linear model by a single underlying factor. On the contrary, if all the values carry negative sign, it shows that they poorly contribute to feature contents in the same magnitude in all the images. Hence, interpreting composite images with similar characteristics like this will not give useful information to discern between different rock materials.

So, PC selection is interplay of the strength of the PC and the signs of eigenvalues of bands 10, 12, and 14. In PC1, bands 10 and 12 meet the positive sign condition, but band 14 does not because of dissimilarity in the information content compared to bands 10 and 12 . In PC2, only band 12 satisfied the required positive contribution condition that information in the input bands must be correlated. So, PC2 is not informative enough to distinguish content richness of quartz rocks. In the case of $\mathrm{PC} 3$, it can be observed that bands 12 and 14 have high contribution while band 10 appears weak. However, the negative value $(-0.296201)$ in band 10 in PC3 can significantly contribute to identifying quartz content richness better than that of band 10 in PC2. This therefore makes PC3 a valuable input for this study. Contrary to the first three PCs, none of the bands in PC4 meets the positive/negative sign condition, so they cannot contribute to identifying quartz content. Despite this, it is very useful in this process because it can distinctively highlight other rock elements in dark pixels and therefore increases background visibility [27]. The last one, PC5, does not have substantial information value to contribute to identifying quartz rock richness because of the noise content. On the final analysis, PC1, PC3, and PC4 satisfied the enabling conditions to identify quartz-rich and quartz-poor rocks. These optimal PCs were used for R(PC3), G(PC1), and B(PC4) false colour composite to reveal variation in quartz content in the rocks. The composite image is presented in Figure 4.

PCs false colour composite image deciphers quartz-rich rocks from quartz-low rocks. For instance, deep blue colour depicts rocks that are highly rich in quartz content. This corroborates [9] who observed that CP composite reveals 


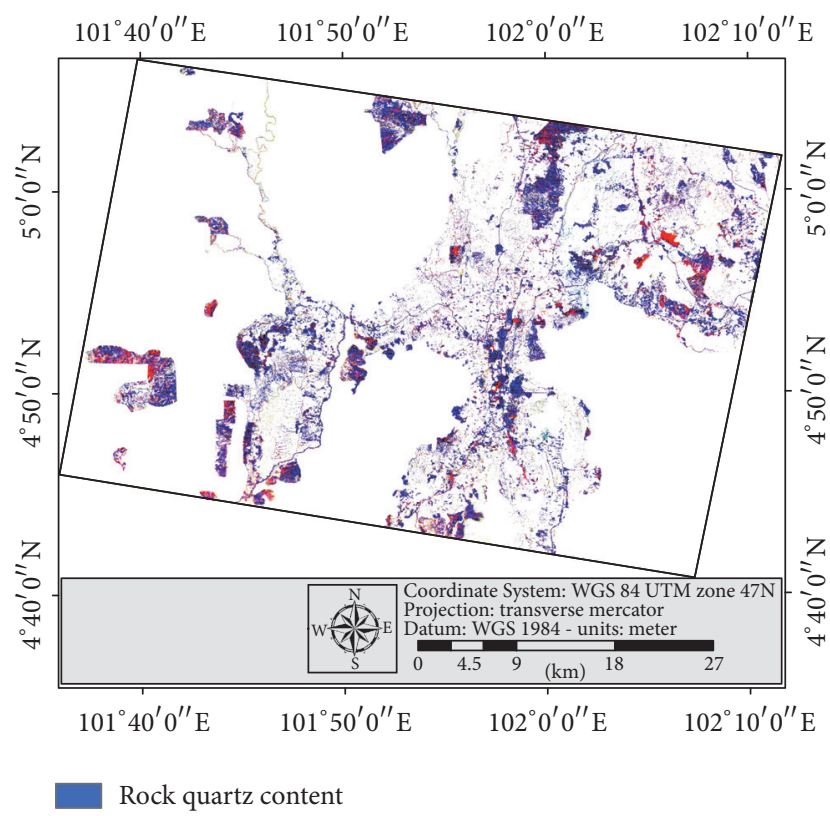

FIgUre 4: RGB false colour composite of PC3, PC1, and PC4. Deep blue colour indicates quartz mineral. The deeper the blue colour the higher the concentration of quartz content, and vice versa.

highly rich quartz content in deep blue. In Figure 4, deep blue colour indicates quartz-rich rocks while yellow colour represents quartz-poor rocks. The deeper the colour the higher the concentration of quartz mineral; however, as the colour becomes lighter, quartz concentration decreases. In the figure, Triassic sedimentary rock has high concentration of quartz mineral as opposed to volcanic igneous rock and limestone which are apparently poor in quartz content. In the west of the image, quartz content varies across the area as evidenced in the mixture of light-blue and yellow colours representing both classes of quartz richness content.

4.2. Visualization for Base-Knowledge Analysis. Qualitative assessment of how, precisely, different rocks can be identified was done visually by displaying the greyscale image of $\mathrm{PC1}$ and then, by overlaying shapefile of the geological map of the study area on the greyscale image (Figure 5). The result reveals distinction in spectral absorption and emissivity different rock types in varying shades of greyscale as presented in Figure 5. For example, the volcanogenic igneous rock, metamorphic, and sedimentary limestone have high ability to emit thermal radiation energy, hence producing brighter greyscale. On the other hand, the composition of organic minerals in sedimentary rock absorbs most of the thermal energy resulting in low emissivity and therefore darker shades of grey. Analysis of the PCs colour composite and the greyscale images were used in identifying rock types and their quartz concentration. Result of this qualitative assessment was validated by overlaying shapefile of the existing geological map on the greyscale image (Figure 5) that shows correct match between the spatial distribution of rock types and their spectral delineation in the remote

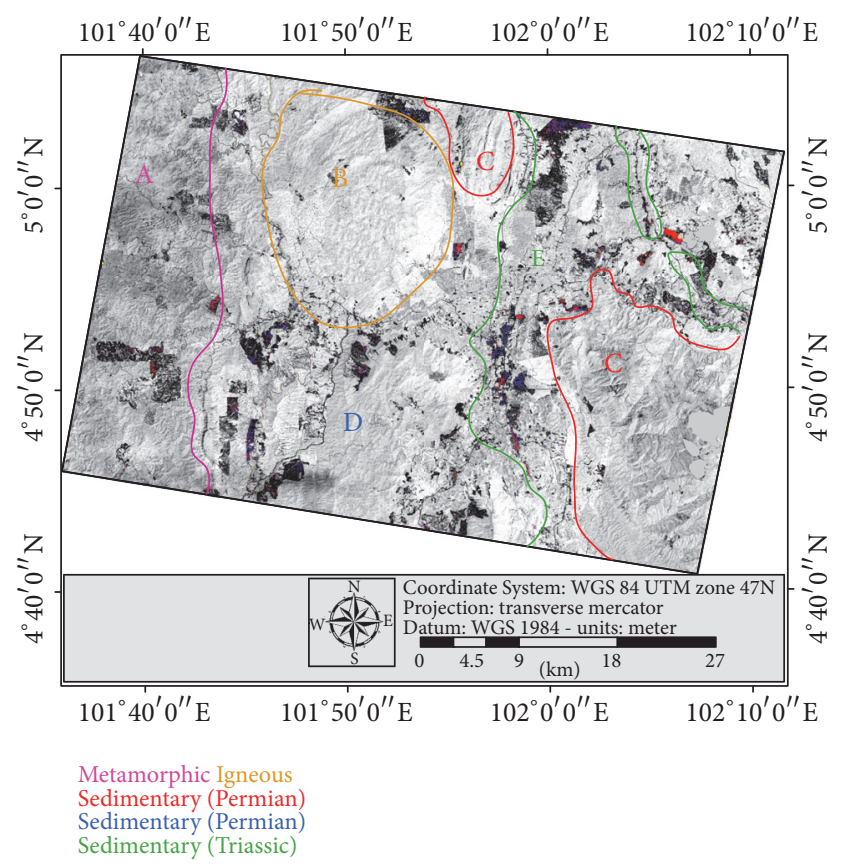

FIGURE 5: Existing geological map superimposed on PCI1 image for rock type identification.

sensing product. Information from the qualitative validation was helpful in selecting training pixels for classification.

Different types of rocks including igneous, sedimentary, and metamorphic rocks carpet the surface and of course subsurface of Kelantan [11, 14, 31]. The distribution of quartz content richness obtained through spectral transformation and rock type identification were presented in Figures 4 and 5. It was observed that quartz mineral is unevenly distributed between the different rock types in the study area. While some rocks have high concentration of quartz, some are not. Visualizing image of $\mathrm{PC1}$ in greyscale highlights the background rock with clear visual perception of different rocks that reflects the strength of absorption/emissivity of ASTER thermal bands [20]. Shades of grey from dark (black) to bright (white) colours provide visual assessment of spatial distribution of rocks with closely related mineral elements (Figure 5). High correspondence of the distribution of rocks in space and extent in the base map (existing geological map) and the spectral transform results shows that the method is not only capable of revealing quartz richness, it can equally discriminate between different rocks.

In Figure 5, the western side which trends north-south (letter A) comprises metamorphic rock. According to studies conducted by Oliver et al. and Zaw et al. [32, 33], the metamorphic rock in this area consists of schist, slate, phyllite, and other associated mineral elements that resulted from intense pressure between the igneous and sedimentary rocks over time to the current texture, structure, and composition. Normally what controls the quartz content in metamorphic rock is the depositional composition during the conversion of sediments to sedimentary rock [16]. So, the presence of sandstone in the metamorphic rock accounts for the presence 
of quartz mineral, although not as high as found in the quartzrich sedimentary rock.

Also, it can be seen that the rock around the locations labelled B and C appear bright in the image. B is mainly igneous rock formed through consolidated molten magma from volcanic activities before the late Triassic or in the late to early Permian [22], which contains coarse-grained granite, textured with tough and rough surface. For C, the rock is purely Triassic sedimentary limestone formed mostly of pyroclastic particles and calcite deposited in layers [13], with rough surface coarser and therefore brighter than the igneous rock. They both contain low organic particles and much of oxidized rock elements that have high thermal emissivity. The Permian sedimentary rock around D appears a little brighter because of low organic material compared to its Triassic counterpart that is darker due to active absorption action of the large organic component in the rock.

The dominant quartz-rich sedimentary rocks are composed of limestone of the Triassic geologic period enriched with laminating shale, sandstone, and dolomite bonded by cementation rather than pressure [22]. A combination of depositional elements and the diagenetic processes determine the mineralogy of a reservoir. The depositional environment of the Triassic sedimentary rock in the study area is dominated by sandstone which is controlled by large percentage of quartz element, starting from south of the central area and trends northeast. From the foregoing analysis, ASTER data, specifically the TIR bands, demonstrates high potential to distinguish different rock types and their quartz content using spectral transformation. It is interesting to note that the procedure has capability to highlight grain level details of quartz element in rocks. However, it is important to understand that when using optical remote sensing imagery, the result may vary according to season of the year. For instance, physical and chemical properties of the rocks may be disbanded and change from under heavy precipitation and heat depending on their crystal structure. Because of the relative stability, seasonal change is not that a challenge for mapping quartz mineral using remote sensing imagery. Nevertheless, when the minerals come in any indirect contact with weak acid water which is the case in tropical region, quartz mineral is more prone to weathering.

\section{Conclusion}

As mentioned earlier, the lithospheric characteristic of the study area includes the igneous, sedimentary, and metamorphic rocks. Exploration of the ASTER thermal bands reveals these different rocks and their quartz content richness. The general observation is that the distribution of quartz among the different rocks is quite uneven. While the pyroclastic volcanic igneous rock and the carbonate dominated Permian sedimentary rocks are quartz-poor, almost void, the Triassic sedimentary rock largely composed of sandstone is quartzrich. On the other hand, metamorphic rock shows variation across the spatial extent having some grains of quartz content with some quartz-rich patches within. Also, the PC greyscale image enhanced surficial background highlighted agrees well with the known geologic information of the area. Obviously, sandstone depositional sedimentary rock of the Triassic formation is more associated with high concentration of quartz than other rocks.

\section{Conflicts of Interest}

The authors declare that they have no conflicts of interest.

\section{Acknowledgments}

This research was supported by the Ministry of Higher Education, Malaysia, under Exploratory Research Grant Scheme ERGS/1/2013/STWNO6/UPM/02/2 and the University Putra Malaysia (Vote no. 5527147). The authors would like to express their gratitude to the Department of Minerals and Geoscience Malaysia (JMG) and the Department of Survey and Mapping Malaysia (JUPEM) for providing various essential datasets used in this study and also to Land Processes Distributed Active Archive Center (LP DAAC) for providing ASTER L1B imagery used in this study.

\section{References}

[1] T. I. R. Almeida, C. R. S. Filho, C. Juliani, and F. C. Branco, "Application of remote sensing to geobotany to detect hydrothermal alteration facies in epithermal high-sulfidation gold deposits in the Amazon region," in SEG Reviews in Economic Geology, R. Bedell, A. P. Crósta, and E. Grunsky, Eds., vol. 16, pp. 135-142, Society of Exploration Geophysicists, Tulsa, Okla, USA, 2009.

[2] A. B. Pour, M. Hashim, and M. Marghany, "Exploration of gold mineralization in a tropical region using Earth Observing-1 (EO1) and JERS-1 SAR data: a case study from Bau gold field, Sarawak, Malaysia," Arabian Journal of Geosciences, vol. 7, no. 6, pp. 2393-2406, 2014.

[3] F. D. van der Meer, H. M. A. van der Werff, F. J. A. van Ruitenbeek et al., "Multi-and hyperspectral geologic remote sensing: a review," International Journal of Applied Earth Observation and Geoinformation, vol. 14, no. 1, pp. 112-128, 2012.

[4] E. E. Mshiu, C. Gläßer, and G. Borg, "Identification of hydrothermal paleofluid pathways, the pathfinders in the exploration of mineral deposits: a case study from the Sukumaland Greenstone Belt, Lake Victoria Gold Field, Tanzania," Advances in Space Research, vol. 55, no. 4, pp. 1117-1133, 2015.

[5] A. B. Pour and M. Hashim, "The application of ASTER remote sensing data to porphyry copper and epithermal gold deposits," Ore Geology Reviews, vol. 44, pp. 1-9, 2012.

[6] L. L. Tornabene, J. E. Moersch, G. R. Osinski, P. Lee, and S. P. Wright, "Spaceborne visible and thermal infrared lithologic mapping of impact-exposed subsurface lithologies at the Haughton impact structure, Devon Island, Canadian High Arctic: applications to Mars," Meteoritics and Planetary Science, vol. 40, no. 12, pp. 1835-1858, 2005.

[7] S. Gad and T. Kusky, "ASTER spectral ratioing for lithological mapping in the Arabian-Nubian shield, the Neoproterozoic Wadi Kid area, Sinai, Egypt," Gondwana Research, vol. 11, no. 3, pp. 326-335, 2007.

[8] A. B. Pour and M. Hashim, "Identification of hydrothermal alteration minerals for exploring of porphyry copper deposit using ASTER data, SE Iran," Journal of Asian Earth Sciences, vol. 42, no. 6, pp. 1309-1323, 2011. 
[9] M. Pournamdari, M. Hashim, and A. B. Pour, "Spectral transformation of ASTER and Landsat TM bands for lithological mapping of Soghan ophiolite complex, south Iran," Advances in Space Research, vol. 54, no. 4, pp. 694-709, 2014.

[10] A. B. Pour and M. Hashim, "Identifying areas of high economicpotential copper mineralization using ASTER data in the Urumieh-Dokhtar Volcanic Belt, Iran," Advances in Space Research, vol. 49, no. 4, pp. 753-769, 2012.

[11] D. A.-F. Batchelor, "Geological characteristics of the Pulai alluvial gold deposit, South Kelantan, Malaysia," Journal of Southeast Asian Earth Sciences, vol. 10, no. 1-2, pp. 101-108, 1994.

[12] D. A. Nazaruddin, N. S. Fadilah, and Z. Zulkarnain, "Geological studies to support the tourism site: a case study in the Rafflesia Trail, near Kampung Jedip, Lojing Highlands, Kelantan," International Journal of Geosciences, vol. 5, pp. 835-851, 2014.

[13] G. S. Heng, T. G. Hoe, and W. F. W. Hassan, "Gold mineralization and zonation in the state of Kelantan," Bulletin of the Geological Society of Malaysia, vol. 52, pp. 129-135, 2006.

[14] B. Li, S.-Y. Jiang, H.-Y. Zou, M. Yang, and J.-Q. Lai, “Geology and fluid characteristics of the Ulu Sokor gold deposit, Kelantan, Malaysia: implications for ore genesis and classification of the deposit," Ore Geology Reviews, vol. 64, no. 1, pp. 400-424, 2015.

[15] K. Shah, "Mesothermal lode gold deposit Central Belt Peninsular Malaysia," in Earth Sciences, D. Imran Ahmad, Ed., pp. 314342, InTech, 2012.

[16] S. Yusoff, B. Pradhan, M. A. Manap, and H. Z. M. Shafri, "Regional gold potential mapping in Kelantan (Malaysia) using probabilistic based models and GIS," Open Geosciences, vol. 7, no. 1, pp. 149-161, 2015.

[17] A. B. Pour and M. Hashim, "Structural geology mapping using PALSAR data in the Bau gold mining district, Sarawak, Malaysia," Advances in Space Research, vol. 54, no. 4, pp. 644654, 2014.

[18] S. S. Matar and A. O. Bamousa, "Integration of the ASTER thermal infra-red bands imageries with geological map of Jabal Al Hasir area, Asir Terrane, the Arabian Shield," Journal of Taibah University for Science, vol. 7, no. 1, pp. 1-7, 2013.

[19] TheQuartzPage, “The Quartz Page: Quartz as a Rock-Forming Mineral," The Quartz Page, 2014 http://www.quartzpage.de/ gen_rock.html.

[20] Y. Ninomiya and B. Fu, "Regional scale Lithologic mapping in western Tibet using ASTER thermal infrared multispectral data," in Proceedings of the Technical Commission VIII Symposium on Networking the World with Remote Sensing (ISPRS '10), vol. 38, pp. 454-458, August 2010.

[21] H. Tonooka, S. J. Hook, T. Matsunaga, S. Kato, E. Abbott, and H. Tan, "ASTER/TIR vicarious calibration activities in the last 11 years," in Proceedings of the IEEE International Geoscience and Remote Sensing Symposium (IGARSS '11), pp. 3653-3656, July 2011.

[22] E. A. Bahiru, Inter-relationship between lithology and structure and its control on gold mineralization in Buhweju area, SW of Uganda [thesis], University of Twente, 2011.

[23] A. Koç, Remote Sensing Study of Surgu Fault Zone (Malatya, Turkey), Middle East Technical University, 2005.

[24] Q. Cheng, G. Bonham-Carter, W. Wang, S. Zhang, W. Li, and X. Qinglin, "A spatially weighted principal component analysis for multi-element geochemical data for mapping locations of felsic intrusions in the Gejiu mineral district of Yunnan, China," Computers and Geosciences, vol. 37, no. 5, pp. 662-669, 2011.
[25] A. B. Pour and M. Hashim, "Application of advanced spaceborne thermal emission and reflection radiometer (ASTER) data in geological mapping," International Journal of Physical Sciences, vol. 6, no. 33, pp. 7657-7668, 2011.

[26] C. Kwang, E. Osei Jnr, and A. Duker, "Application of remote sensing and geographic information systems for gold potential mapping in birim North District of Eastern Region of Ghana -gold potential mapping using GIS and remote sensing," International Journal of Remote Sensing Applications, vol. 4, no. 1, p. 48, 2014.

[27] A. Ezzati, R. Mehrnia, and K. Ajayebi, "Detection of Hydrothermal potential zones using remote sensing satellite data in Ramand region, Qazvin Province, Iran," Journal of Tethys, vol. 2, no. 2, pp. 93-100, 2014.

[28] L. Bertoldi, "Remote Sensing of granitoid rocks: image elaboration and spectral signatures (Morocco calc-alkaline, Corse and Himalayan peraluminose granitoid case studies)," Interpret. A J. Bible Theol., 2010.

[29] N. Surip, A. H. Hamzah, M. R. Zakaria, A. Napiah, and J. A. Talib, "Mapping of gold in densely vegetated area using remote sensing and GIS techniques in Pahang, Malaysia," Open Geosciences, vol. 7, pp. 149-161, 2015.

[30] R. Amer, T. Kusky, and A. El Mezayen, "Remote sensing detection of gold related alteration zones in Um Rus area, central eastern desert of Egypt," Advances in Space Research, vol. 49, no. 1, pp. 121-134, 2012.

[31] B. He, C. Chen, and Y. Liu, "Gold resources potential assessment in eastern Kunlun Mountains of China combining weights-ofevidence model with GIS spatial analysis technique," Chinese Geographical Science, vol. 20, no. 5, pp. 461-470, 2010.

[32] G. Oliver, K. Zaw, M. Hotson, S. Meffre, and T. Manka, "U-Pb zircon geochronology of Early Permian to Late Triassic rocks from Singapore and Johor: a plate tectonic reinterpretation," Gondwana Research, vol. 26, no. 1, pp. 132-143, 2014.

[33] K. Zaw, S. Meffre, C.-K. Lai et al., "Tectonics and metallogeny of mainland Southeast Asia-a review and contribution," Gondwana Research, vol. 26, no. 1, pp. 5-30, 2014. 


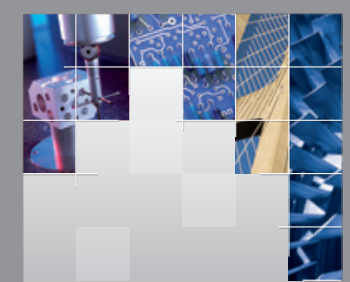

\section{Enfincering}
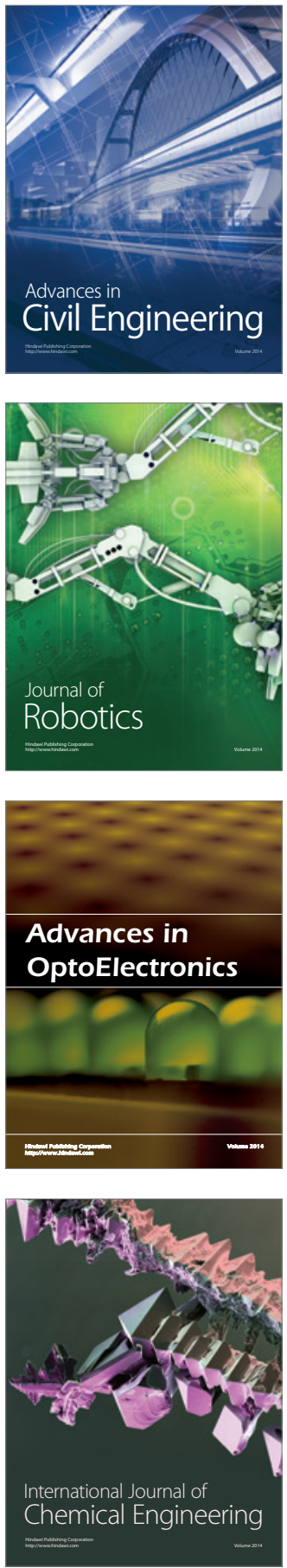

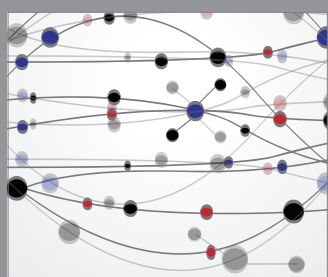

The Scientific World Journal

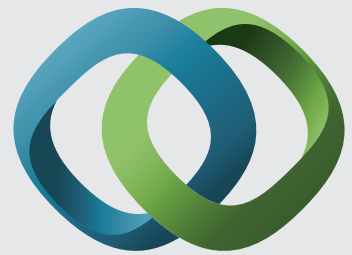

\section{Hindawi}

Submit your manuscripts at

https://www.hindawi.com
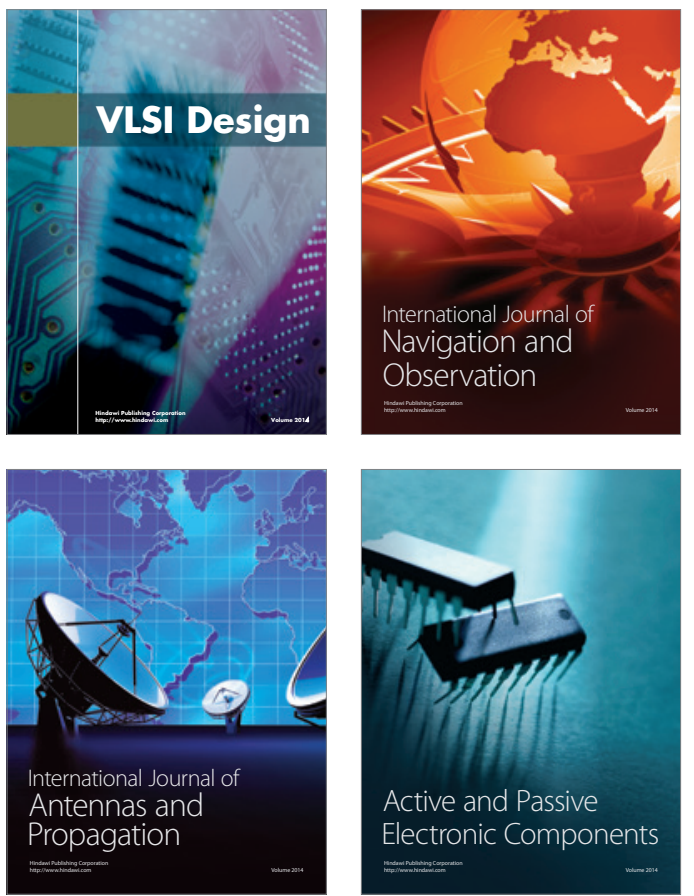
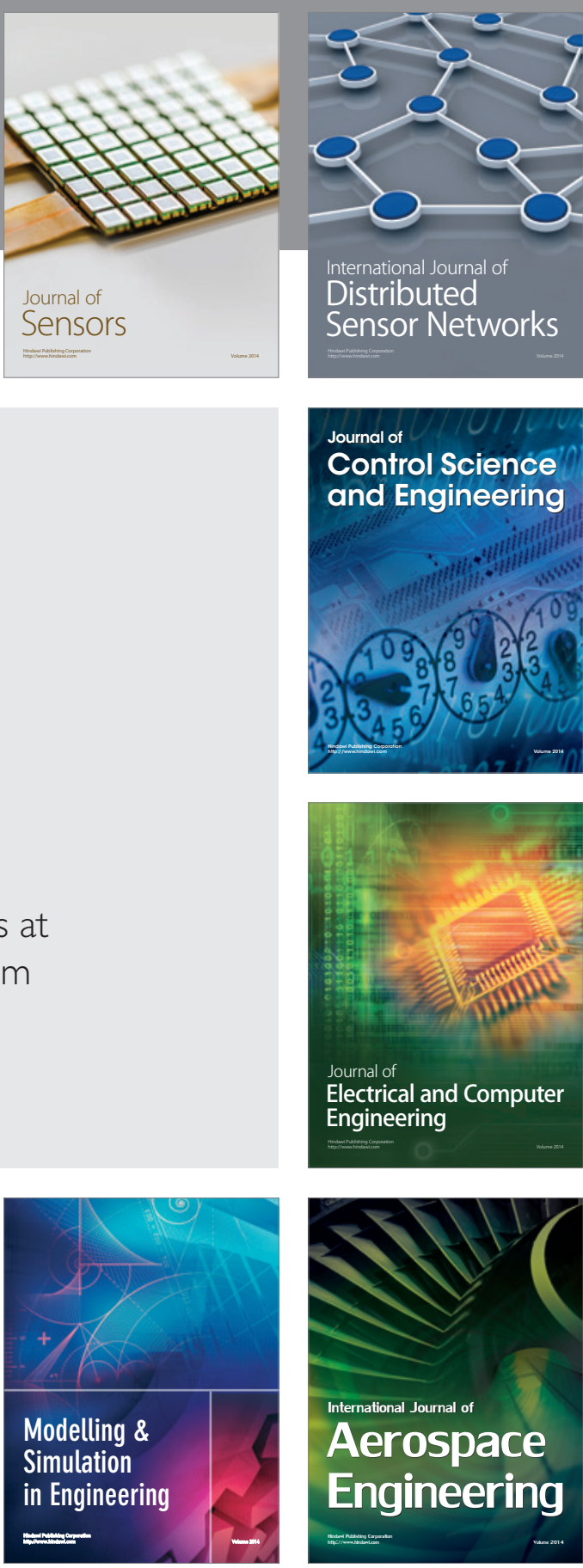

International Journal of

Distributed

Sensor Networks

$-$

Joumal of

Control Science

and Engineering
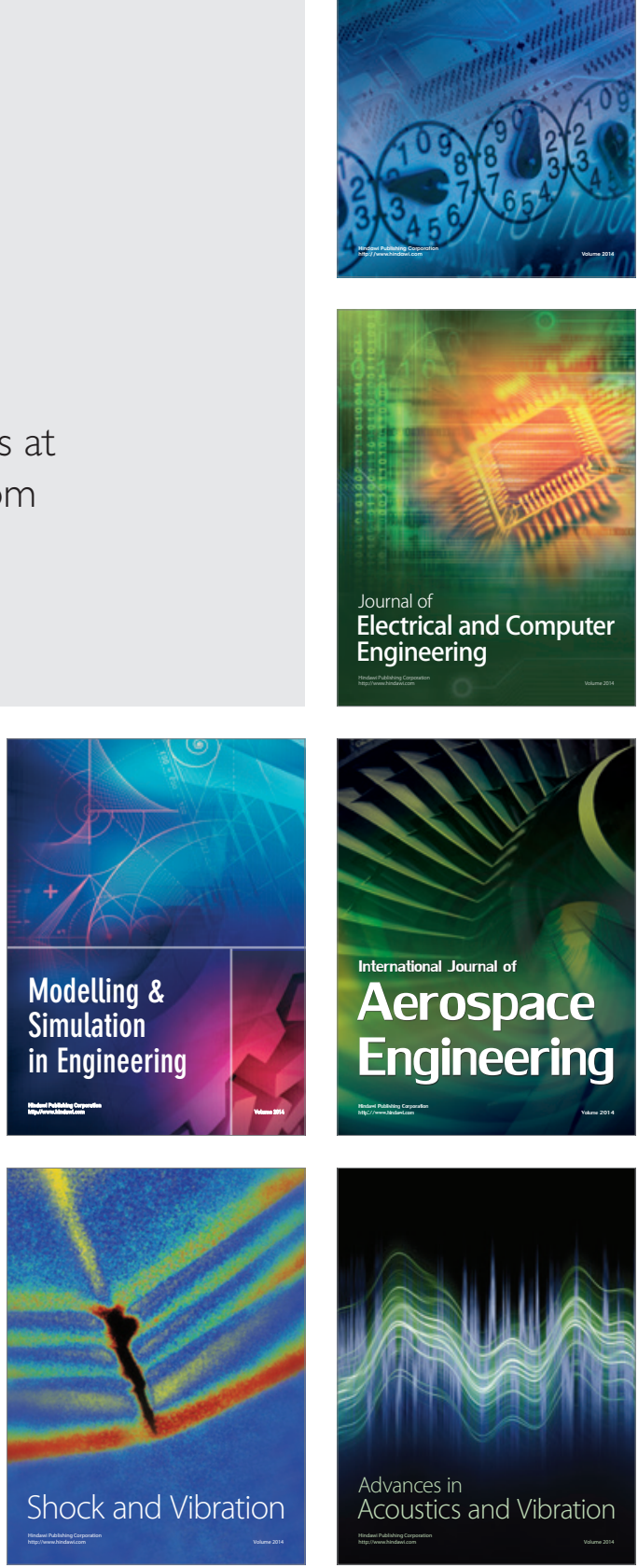